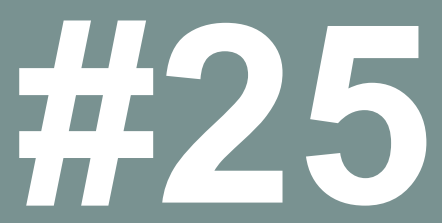

\title{
NARRAR LA \\ PRECARIEDAD: \\ CRISIS DEL SUJETO Y \\ SUBVERSIÓN DEL \\ ORDEN DOMINANTE EN \\ YO, PRECARIO (2013), \\ DE JAVIER LÓPEZ \\ MENACHO*
}

Claudio Moyano Arellano

Universidad de Valladolid 


\section{$4520 \mathrm{~F}$}

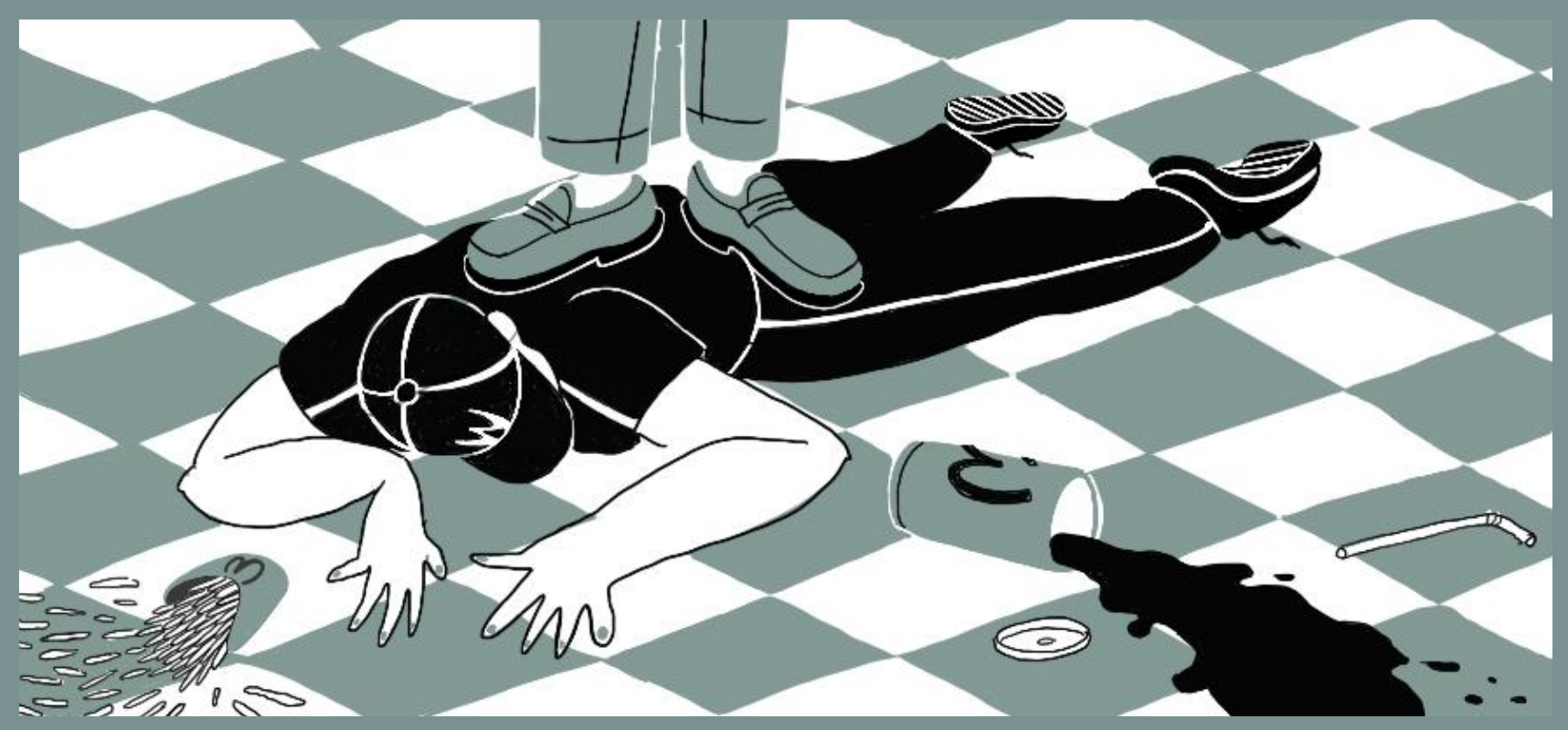

Resumen || El presente artículo analiza la novela de Javier López Menacho, Yo precario (2013) como una de las novelas de la precariedad más relevantes. En primer lugar, se relaciona esta novela con la teoría de Guy Standing sobre el surgimiento de una nueva clase social, el precariado. En segundo lugar, se ilustra cómo el protagonista de la novela es un sujeto en crisis por diversos motivos: la alienación respecto a su trabajo, la dificultad de establecer lazos solidarios con sus compañeros y una relación enfermiza con el espacio y tiempo de su práctica laboral. Por último, se defiende cómo la novela plantea una vía de resistencia y subversión a través del humor, la ironía y la metaliteratura.

Palabras clave || Novela de la precariedad | Realismo crítico | El precariado | Novela española contemporánea | Javier López Menacho

\section{Narrating Precarity: The Crisis of the Subject and the Subversion of the Dominant Order in Yo, precario (2013) by Javier López Menacho}

Abstract || This article analyzes Yo, precario (2013), a novel by Javier López Menacho, as one of the most relevant «novels of precarity». Firstly, it relates the novel to Guy Standing's theory of the emergence of a new social class, the precariat. Secondly, the article illustrates how the protagonist of the novel is a subject in crisis due to a variety of reasons: alienation from his work, the difficulty of establishing links of solidarity with his colleagues, and an unhealthy relationship with the space and time of his work practice. Finally, it argues that the novel puts forward a means of resistance and subversion through humor, irony and metaliterature.

Keywords || Novel of Precarity | Critical Realism | The Precariat | Contemporary Spanish Novel | Javier López Menacho

\section{Narrar la precarietat: crisi del subjecte i subversió de l'ordre dominant a Yo, precario (2013), de Javier López Menacho}

Resum || El present article analitza la novel·la de Javier López Menacho, Yo precario (2013), com una de les novel-les de la precarietat més rellevants. En primer lloc, es relaciona aquesta novel la amb la teoria de Guy Standing sobre el sorgiment d'una nova classe social, el precariat. En segon Iloc, s'il·lustra com el protagonista de la novel-la és un subjecte en crisi per diversos motius: l'alienació respecte del seu treball, la dificultat d'establir llaços solidaris amb els seus companys i una relació malaltissa amb l'espai i el temps de la seva pràctica laboral. Per últim, es defensa com la novel·la planteja una via de resistència i subversió a través de l'humor, la ironia i la metaliteratura.

Paraules clau || Novel·la de la precarietat | Realisme crític | El precariat | Novel·la espanyola contemporània | Javier López Menacho 


\section{Introducción: esbozo de un marco teórico-crítico de análisis de la novela de la precariedad}

Javier López Menacho publicó en 2013 su novela, Yo, precario, con buena acogida por parte de la crítica y del público; no obstante, y a pesar del indudable auge que está viviendo hoy la «novela de la crisis» en España, parece que la obra de López Menacho ha pasado a ocupar un segundo plano en los estudios críticos sobre dicho fenómeno. Este artículo pretende, en primer lugar, resaltar las indudables cualidades narrativas de esta obra, aunque su objetivo central sea entender dicha obra como epítome de la novela del precario, y estudiar en ella tanto la articulación de la denuncia de las condiciones que impone el mercado laboral actual, no solo español, como el surgimiento de una nueva clase social, el precariado. Es indudable que la novela española está experimentando un auge de textos que están reflexionando sobre las condiciones materiales y productivas de los trabajadores: autores y autoras como Belén Gopegui, Marta Sanz, Isaac Rosa, Elvira Navarro, y más recientemente, Sara Mesa, Cristina Morales y Elena Medel (con su primera $\mathrm{y}$, hasta la fecha, última novela, Las maravillas), sobresalen dentro de este fenómeno en el que la novela de López Menacho merece, como se demostrará posteriormente, ser tenida muy en cuenta. No es baladí, tampoco, mencionar cómo estas novelas conectan con el realismo social español de los años 50 y 60, y recuperan su tradición vindicativa, aunque con evidentes diferencias cuyo estudio desbordaría las pretensiones de este trabajo.

Para comprender, en líneas generales, la respuesta que desde los discursos culturales se dio a la crisis financiera del 2008, momento importante que marca gran parte de la producción narrativa a la que se está aludiendo, es interesante el artículo de Valdivia (2016), quien, aunque no menciona la novela de López Menacho, entiende bien la relación entre la novela como resistencia y la situación social y política del momento, al afirmar que:

Las narraciones culturales de esta coyuntura de crisis y de renovación habilit[a]n no sólo espacios de resistencia y de consumo diversos o propici[a]n la posibilidad de ámbitos discursivos alternativos, sino que además construyen y describen la realidad cognitiva en la que nos inscribimos social e intelectualmente (2016: 22).

El análisis de la novela Yo, precario que se propone se centra en cómo se construye un sujeto en descomposición debido, precisamente, a esas condiciones laborales, y cómo este intenta sobreponerse a la disolución de su propia subjetividad. Porque, cuando se afianza la identidad entre el hombre —entendido como el ánthropos griego, en sentido genéricoy el trabajo, y este falla, ¿qué sucede con el propio sujeto? Así, el protagonista de la novela sostiene lo siguiente:

Tengo casi treinta años y siento que me han robado la esencia. Tiene que ver con el trabajo. En algún momento interioricé que sólo es hombre quien trabaja y puede hacerse cargo de sí mismo. Yo no tengo trabajo estable y ni siquiera he aprendido a cuidar de mí. Mi único activo es no poseer nada (2013: 83). 
Esta novela está protagonizada por un precario. «El precariado» es el término con el que el economista británico Guy Standing (2018) ha titulado una de sus obras más relevantes, con la que ha actualizado los términos del estudio de la estratificación social. Standing señala que si bien precariado es un «neologismo que combina el adjetivo "precario" y el sustantivo "proletariado"» (2018: 26), el precariado difiere mucho de la "clase obrera tradicional» porque esta se caracterizaba por un puesto de trabajo «duradero y estable, con jornadas de trabajo fijas y vías bastantes claras de mejora, sindicados y con convenios colectivos, cuyos puestos de trabajo tenían un nombre que sus padres y madres habrían entendido» (2018: 24). Por el contrario, el precariado ya no responde a este esquema, tablero de juego en el que tanto el proletariado como la llamada «clase media» han quedado diluidos.

Standing recoge hasta siete formas de seguridad relacionadas con el trabajo de las que puede carecer alguien para entrar dentro de la categoría del «precariado» (2018: 30-31). En mi opinión, lo que singulariza a esta nueva clase social es principalmente la conjunción de los siguientes tres factores: inseguridad en los ingresos (y no importa tanto si estos pueden ser elevados en un momento puntual cuanto la falta de certeza de la que el trabajador adolece con relación a cuándo va a cobrarlos), absoluta inestabilidad en su puesto de trabajo y completa falta de identidad relacionada con el trabajo, carencia de «identidad ocupacional» (2018: 34). Estos tres factores contribuyen, todos ellos, a quebrar la identidad del protagonista de la novela de López Menacho, un álter ego del propio autor, personaje que, además, se siente doblemente fracasado, porque su condición de precario se impone a pesar de «tener una carrera, un máster y varios cursos de investigación» (2013: 17).

Se acaba de señalar que el protagonista de la novela es un álter ego del autor. En este sentido, ¿qué pacto de lectura plantea esta novela? Obviamente, si se recurre al estudio ya clásico de Alberca (2007), hay que indicar que el pacto que se pretende establecer entre la obra y los lectores es un pacto ambiguo, a caballo entre el pacto autobiográfico en el que el autor se responsabiliza de la veracidad de lo que narra, aseverando que se narran los hechos tal y como los recuerda el autor en ese momento- - y el pacto de ficción —en el que la pregunta por la verdad pierde sentido en favor de la verosimilitud y la coherencia-, como sucede con las denominadas «novelas del yo» (2007: 64-72), que Vicente Luis Mora (2013) ha estudiado de forma global a través de uno de los símbolos más potentes: el espejo.

Por un lado, la génesis de esta novela es, cuando menos, reseñable, y así nos informa de ella el propio autor en la introducción de la obra: después del fracaso de una empresa dedicada a la animación para el tiempo libre, y tras mudarse a Barcelona en aras de mejorar sus oportunidades laborales, comenzó a trabajar como mascota en la promoción de una marca de chocolatinas entre los meses de marzo y abril de 2012; y así afirma lo siguiente: "con veintinueve años y unas perspectivas laborales lamentables, me lancé a trabajar de mascota, y a escribir las crónicas nada más llegar a casa. Así nacieron las "chococrónicas"» (López Menacho, 2013: 17-18). Unas crónicas que, 
quizá influido por el curso sobre «periodismo gonzo» que estaba recibiendo cuando comenzó a escribirlas, en ningún momento tratan de narrar la situación vivida con una pretendida neutralidad, sino que el autor de ellas, testigo de la sociedad y, a la vez, protagonista del trabajo, interviene decididamente con su subjetividad en la construcción de los textos. Periodismo y literatura fundidos hasta que los límites de ambos se hacen indistinguibles.

Por tanto, sabemos que los datos biográficos que se dan en esta introducción y, en ocasiones, a lo largo de la obra (por ejemplo, se alude brevemente a un hermano mellizo [2013: 103]) corresponden, efectivamente, al autor real, extradiegético; sin embargo, el formato «novela» en el que se leen estas crónicas impide establecer un pacto autobiográfico en puridad, y obliga a leer la obra con un pacto ambiguo, en el que, efectivamente, se establece una equidad entre la voz narradora, el protagonista y el autor, pero en el que la importancia del elemento literario —es decir, ficcional, novelesco- es indudable; así, se vuelve imposible dar primacía a uno de los dos ámbitos, y «es preciso moverse en un ir y venir constante entre esos dos polos: entre la literatura y la vida, entre el narrador y el autor» (Alberca, 2007: 61).

Aclarado este punto, conviene ahondar en la relevancia que supone el hecho de que se haya escogido una «novela del yo» para realizar, a partir de la literatura, una crítica, en ocasiones descarnada, hacia la situación laboral a la que estaban condenados muchos de los jóvenes de España en los primeros años de la década de 2010, y que aún persiste hoy. $Y$ se señala esto porque la autoficción ha sido un recurso muy recurrente -tanto que se ha hablado del "cansancio del yo» (Caballé, 2017), aunque también es cierto que sus propuestas se han diversificado y revitalizado - para plantear debates indudablemente interesantes, como el estatuto epistemológico de la ficción, la diferencia entre literatura e historia $y$, finalmente, para reflexionar sobre las fronteras entre la realidad y la ficción, en un elenco enorme de nombres en el que se podrían destacar a Javier Cercas, Antonio Muñoz Molina, Enrique Vila-Matas o Javier Marías, entre otros.

No obstante, el uso de este recurso para plantear una crítica social a la situación ya descrita constituye un acertado ejercicio de «caballo de Troya» narrativo. Como señala David Becerra, apoyándose en Belén Gopegui, al reflexionar sobre las posibilidades de cultivar una literatura que intente subvertir la ideología dominante, una de las maneras de cultivar dicha literatura revolucionaria o, al menos, revulsiva, combativa, es "disfrazarla» según los moldes de la literatura dominante, y asumir algunos de sus rasgos; así, "el caballo tiene que tener forma de caballo», pero no únicamente «para cruzar las murallas de la ciudad enemiga, sino también para que el discurso subversivo pueda llegar con mayor facilidad a sus lectores potenciales» (Becerra et al., 2013: 47).

Así, en Yo, precario, se encuentran, además de una novela que encaja perfectamente en todas las costuras del molde de la autoficción, elementos propios de la literatura dominante: un orden narrativo, en cierta medida, convencional, al igual que su estructura espaciotemporal, 
una tendencia al sentimentalismo y una fuerte presencia de la ironía. Sin embargo, como se verá en este análisis, también estos recursos están puestos al servicio de una literatura que pretende convulsionar a quien lea la obra, pues la ironía alcanza cotas subversivas y la temporalidad, en muchas ocasiones, refleja una enfermiza tendencia a la rutina y a la circularidad.

Convulsionar, importunar, molestar a los lectores son claros objetivos de una novela crítica con la sociedad en la que se produce. En este sentido, Juan Carlos Rodríguez nos ha legado dos ideas de enorme importancia. La primera de ellas es la «radical historicidad de la literatura», pues los discursos literarios «están siempre - y únicamente - segregados desde (y determinados por) las necesidades específicas de una matriz ideológica históricamente dada» (Rodríguez, 2017: 14). Al adentrarnos en la matriz ideológica en la que se produce la última narrativa española, nos topamos con otro elemento decisivo, con claros ecos althusserianos: el «inconsciente ideológico» (Rodríguez, 2013: 99), que Chiara Giordano ha puesto en relación con el «sentido común» gramsciano en el sentido de «una práctica naturalizada, es decir, transformada en espontánea y casi automática por un sistema de costumbres y bajo la supervisión de un "apparato egemonico"» (2018: 69-70). En nuestros días, es claro cómo ese «inconsciente ideológico» se identifica, hasta confundirse, con el capitalismo y el liberalismo. Se verá en el análisis posterior cómo, desde estos presupuestos, de los que obviamente tampoco escapa López Menacho, se puede construir un texto disidente.

En último término, es visible cómo se entiende claramente la novela como un vehículo estético que no se agota en su condición de artificio, ni siquiera tampoco en su posibilidad de convertirse en un texto de reflexión sociopolítica; la novela se conceptualiza como un discurso explicativo de la realidad, con capacidad de intervención sobre ella. Obviamente, "la ficción siempre tiene consecuencias» (Gopegui, 2019: 252) y no existe una posible neutralidad desde la que narrar una historia, mucho menos aún cuando esa historia apela al propio autor: es una quimera que conviene desterrar de una vez por todas. Todas las formas de discurso, también el literario, contienen siempre ideología (Becerra, 2013: 9). En Yo, precario, claramente hay un objetivo primero por parte del autor, y es el de catarsis ante unas precarias situaciones laborales que no solo no son circunstanciales, sino que comienzan a convertirse en su forma de vida (López Menacho, 2013: 18). Sin embargo, el texto también sirve como explicación de una realidad que sobrepasa al autor $\mathrm{y}$, en segundo lugar, como intento de subvertir un statu quo con el que se está en desacuerdo.

Importa también destacar, aunque sea brevemente, cómo este análisis entronca con la recuperación de la retórica y, en concreto, con la retórica constructivista, que en nuestros días ha propuesto con acierto Pujante (2018), quien defiende cómo la realidad es construida a partir de los distintos discursos que los seres humanos articulamos, en primer lugar, para explicarnos a nosotros mismos el mundo en el que vivimos $y$, posteriormente, para persuadir a los demás de que nuestra visión de ese mundo, nuestra interpretación, es la correcta, y más después de la caída 
de los grandes relatos (Lyotard, 2006) y la constatación de que la verdad monológica, unívoca, no debe tener cabida en democracia, por el riesgo de autoritarismo que eso supone (Vattimo, 2010: 18). Por supuesto, la novela — toda la literatura, de hecho- es uno de esos discursos que también posee capacidad suasoria, y de ello dan muestra elementos como, por ejemplo, la importancia de la construcción de la trama narrativa o la relevancia que alcanza la elocutio, no concebida en absoluto ya como mero adorno o sermo ornatus, sino como la operación discursiva cuya reivindicación nos permite «el retorno a la confianza en la palabra como capaz de decir aquello que sentimos como más verdadero» (Pujante, 2018: 15; cf.: Pujante, 2011). En ningún caso se puede mantener la dicotomía insalvable entre el fondo y la forma, ni mucho menos la defensa del predominio de uno sobre otra, o viceversa. No hay que olvidar que el fondo, el contenido, se determina como tal por la forma en la que se articula. De ahí la importancia de la recuperación y revitalización de la operación elocutiva.

No obstante, hay que hacer una salvedad: no se trata de defender que la propia materialidad de la realidad es construida, pues esto nos abocaría a un excesivo construccionismo que, de alguna forma, desactivaría una potencial intervención política centrada en modificar esas condiciones materiales: no se debe confundir el objeto con la idea (Hacking, 2011: 37). Lo que se construye socialmente no es el objeto, sino la idea de ese objeto (2011: 55-56). Ahora bien, la única forma que tenemos de elaborar un pensamiento en torno a esa materialidad, esto es, un discurso que intente explicar esas condiciones materiales es por medio de la palabra. Ahí radica la relevancia de entender cómo nuestros discursos moldean o construyen esa realidad social en la que vivimos, y por ello, la retórica constructivista es un marco harto adecuado para entender estos textos cuyos autores, en este caso López Menacho, pondrán en juego todos los mecanismos que la ficción permita para convencernos de su cosmovisión, y no solo denunciar la situación. En definitiva, es indudable que el texto literario, "frente a las nociones idealistas de la literatura, contiene un "mensaje", entendido este como el intento por parte del autor de imponer o compartir un concepto del mundo a sus lectores» (Becerra et al., 2013: 25).

Se ha reflexionado sobre el autor y sobre el propio texto literario, pero resta comentar la otra figura fundamental de la literatura: la persona que lee. ¿A qué lectores apela la obra de López Menacho? Si se es consciente de que la lectura no implica únicamente descodificar el mensaje escrito, se convendrá en que existen diferentes clases de lectores y, además, distintos tipos de lecturas. En este sentido, resulta operativa la tipología de lecturas que establece Constantino Bértolo (2008): lectura adolescente, inocente, sectaria, letraherida y civil, además de la lectura del crítico, diferente a las demás porque esta ya no consiste en una lectura privada, sino pública. La lectura a la que apela Yo, precario es, eminentemente, una lectura civil: quienes leen deben estar implicados activamente en su contexto social y político y han de saber conjugar los anteriores tipos de lecturas para, en último lugar, llegar a un conocimiento mejor y más profundo tanto de sí mismos como de su comunidad (2008: 77-113). Al leer, y es indispensable tomar 
conciencia de esto, no se puede recibir pasivamente el texto que se consume: uno tiene que prestarse a la inquietud, al desasosiego, en aras de romper la asunción acrítica de la ideología dominante. Hay responsabilidad en quien escribe, pero también en quien lee. Escritura y lectura son, ambas, eminentemente políticas.

A modo de colofón de este epígrafe introductorio, en este trabajo se analiza la novela de López Menacho siguiendo dos claves de lectura, que representan asimismo las hipótesis de trabajo: en primer lugar, la novela refleja las precarias condiciones laborales a las que se ve abocado un joven periodista español, personaje que actúa de ejemplo, casi metonímico, de una importantísima cantidad de jóvenes españoles abocados a vivir en la más absoluta precariedad; en segundo lugar, se pone de relevancia cómo este personaje que protagoniza la novela, en plena crisis no solo laboral y económica, sino también moral, articula un discurso de resistencia, en el que la ironía tiene un papel fundamental, entendida como tabla de salvavidas arrojada a ese mar laboral que amenaza con extinguirlo y con la que también pretende apelar y mover políticamente a los lectores.

\section{Yo, precario: crisis de la subjetividad y subversión del orden}

En la novela de López Menacho se narra, entre otras cosas, el trabajo de una persona, y por trabajo hay que entender, en este momento, las efectivas condiciones materiales en las que se desarrolla la actividad laboral de un personaje. Hay que insistir en esta idea porque el trabajo manual, el trabajo que desgasta el cuerpo, ha sido raramente tratado en la novela española contemporánea, aunque se haya revitalizado ligeramente como tema narrativo a partir de la crisis la crisis de 2008, como se mencionó al principio de este trabajo. Esta novelística que ha evitado tratar temas laborales, políticos y económicos ha recibido el nombre de «novela de la no-ideología» por parte de David Becerra (2013), si bien no hay novela que no tenga ideología, aunque la intente acallar, pues sabemos que no existe la literatura inocente. Con este membrete, Becerra apela a una novela en la que «toda forma de conflicto social, toda forma de discurso político (ideológico, en este sentido) ha quedado excluido de la novela» (2013: 29).

En Yo, precario, el protagonista de la novela afronta cuatro trabajos, todos ellos a tiempo parcial: mascota de una marca de chocolatinas, auditor de máquinas de tabaco, repartidor de publicidad de una compañía telefónica y speaker-animador de los partidos de fútbol de la Eurocopa proyectados en un cine de Sant Cugat, contratado por una marca de automóviles para la que trabajará promocionándola entre los asistentes (2013: 129 y ss.). A lo largo de la novela, se explica, por ejemplo, cuál es el protocolo que debe seguirse para interactuar con un niño pequeño, qué se debe decir y cómo se debe mover uno dentro del disfraz de mascota (2013: 66) o cómo, trabajando de auditor de máquinas de tabaco, el personaje debe realizar un estudio de mercado de trece días en el que tiene que visitar bares y restaurantes y comprobar qué marcas se venden más (2013: 86 y ss.). Asimismo, además de 
describir la propia materialidad del trabajo, sus propias condiciones de desarrollo, en la novela también se nos habla de sueldos $y$, normalmente, de sueldos muy escasos.

En este sentido, el protagonista explica cómo «cada máquina de tabaco auditada se paga a razón de dos euros. [...] A razón de cuatro establecimientos por hora, puedes llegar a cobrar ocho euros la hora» (2013: 87). También, en el momento en el que empieza a trabajar como reclamo y repartidor de publicidad de una conocida, y cara, compañía telefónica, detalla lo siguiente: «por supuesto, se trata de un contrato [de siete días] a través de terceros [...]. Todo ello por 4,9 euros la hora, el sueldo mínimo que jamás cobré. El precio, a día de hoy, de mi dignidad» (2013: 107-108). Se ve con claridad cómo, además del paupérrimo sueldo que el protagonista recibe como retribución a su trabajo, se dan las condiciones propias del precariado: la completa inestabilidad en el puesto del trabajo, debido a la insoportable temporalidad de los distintos empleos que encadena, y la falta de identidad en relación con esos trabajos. Véase, a continuación, una escena importante dentro de la novela, que pone de manifiesto la vergüenza que siente el protagonista al preguntar si, al final del trabajo, cobrará su sueldo, consciente de los habituales retrasos que suelen darse en este tipo de empleos:

\footnotetext{
En la reunión donde presentan la campaña, lo remarcas con ese tono que disfraza de broma lo que en realidad es un asunto muy serio.

- Eh, ¿cobraremos, verdad? - dices para que vean que tienes experiencia y sabes que luego estas cosas no se cobran o se cobran tarde, porque en la escala de pagos, y aunque cueste creerlo, el más miserable es el menos urgente.

- Hombre, por supuesto - contesta con cara de ofendida la secretaria, [...] casi pensando si no hubiera sido mejor haber contratado a otro, uno que quizás no quisiera cobrar, uno que no levantara la voz (2013: 84-85).
}

Contrasta el reparo que siente el protagonista frente a la respuesta altiva de la secretaria. Remedios Zafra - cuyo ensayo El entusiasmo, si bien es cierto que se dirige a explicar las circunstancias en las que se produce la precariedad en el mundo cultural, aporta también claves para entenderla en sentido general - ha señalado cómo «en algún momento de nuestra historia hablar de dinero cuando uno escribe, pinta, compone una obra o crea se hizo de mal gusto» (2017: 18). A este respecto, cabe destacar que este sentimiento de «mal gusto», impuesto obviamente por el orden dominante, se hace extensible a todos los trabajos, especialmente a los que rozan la esencia misma de la precariedad.

Por tanto, es verdad que, como afirma Becerra, en la novela contemporánea que intenta subvertir la ideología dominante no solo se trata de reflejar la realidad, "sino de describir los velos que la cubren o la opacan» (2015: 15). En último término, como sostiene Gopegui, el arte debe «hacer visible lo visible», porque «no es preciso hablar de poderes ocultos ni de un inconsciente turbio. Basta con hablar del poder visible y de los nombres que lo ostentan y de los medios para arrebatárselo. [...] La opresión es absolutamente visible» (2004). La cuestión radica en por qué supone una novedad, incluso cierta transgresión, que una novela hoy describa las miserables condiciones laborales y económicas en las que vive el protagonista o, por otro lado, por qué otros autores han 
declinado conscientemente cultivar estos temas en sus textos, quizá con la intención de evitar «que algo ensuciara el mundo abstracto y limpio de la obra, aun cuando está hecha de detritus y miseria» (Zafra, 2017: 1819).

Hechos estos comentarios, que son imprescindibles para entender los planteamientos generales tanto de la obra como del trabajo que se pretende en este artículo, se procede, a continuación, a profundizar en el análisis del texto, que se realizará a partir de tres claves que explican la disolución del sujeto (la alienación, la imposibilidad del compañerismo y una espacio-temporalidad enfermiza) y la posibilidad de subversión y resistencia a través de la ironía.

\subsection{El sujeto alienado y cansado}

Ya se ha señalado que una de las características fundamentales del precario es que este carece de todo tipo de relación identitaria con el trabajo que lleva a cabo; es, obviamente, un sujeto alienado. La alienación puede entenderse como la «conversión de los productos de la actividad humana (productos del trabajo, relaciones sociales y políticas, normas de moral, teorías científicas, formas de conciencia social), al igual que de las propiedades y capacidades del hombre, en algo independiente y ajeno a éste y que lo domina» (Blauberg, 1971). En este sentido, es conveniente recurrir a la distinción tripartita que establece Arendt entre labor, trabajo y acción (2005: 35), actividades esenciales que constituyen la vita activa en el ser humano. La labor es la actividad que se encamina a satisfacer las necesidades vitales del individuo y que produce bienes de consumo escasamente perdurables (2005: 107-163). El trabajo, por su parte, es la actividad que fabrica perdurables objetos de uso, instrumentos, muchas veces empleados para llevar a cabo la labor y cuyo empleo no implica su desaparición (2005: 165-203). Respectivamente, tenemos al animal laborans y al homo faber. La acción (y el discurso), por su parte, apela directamente a la propia condición humana y permite la vida política (2005: 35). Arendt va más allá, y afirma que si bien las personas pueden decidir no laborar ni trabajar (un esclavista y un parásito serán sujetos atroces, pero seguirán siendo humanos), no sucede lo mismo con la acción ni con el discurso, pues una vida sin ellos «está literalmente muerta para el mundo; ha dejado de ser una vida humana porque ya no la viven los hombres» (2005: 206).

Después de este recurso a la teoría política arendtiana, se puede comprender mejor la alienación del protagonista de Yo, precario, y es que es imposible que pueda sentirse identificado y responsable de su trabajo porque, en puridad, los empleos que lleva a cabo están más en relación con la labor que con el trabajo, en el sentido de que son actividades con las que no produce nada y que son consumidas en el mismo instante en que cesan. Con ninguno de sus efímeros empleos logra el protagonista sobreponerse a su condición mortal («Con esta otra clase de empleos la satisfacción nunca existe. Lo hagas bien, mal o 
regular» [López Menacho, 2013: 90]). Así lo explica el protagonista de la novela:

Esporádicamente he trabajado, sí, pero a eso no se le puede llamar trabajo: son servicios que prestas para que te exploten y para que tengan trabajo de verdad otros, con el fin de que sus empresas funcionen y ellos puedan llegar a casa con el pan bajo el brazo (2013: 83$)$.

No obstante, aparte de estas consideraciones políticas, la alienación del protagonista también se explica por la degradación que, como sujeto (y sujeto político), está obligado a aceptar en todos los empleos. El comienzo de la novela es claramente sintomático: el personaje, que ha sido aceptado como mascota de una marca de chocolatinas, tiene que quedarse en calzoncillos delante de la coordinadora, situación que él asemeja a aquellos momentos en los que «tu madre te desnudaba sin reparos delante de alguna de sus amigas, o cuando, ya adolescente, te acostabas con alguien por primera vez» (2013: 21). Toda la descripción del disfraz con el que trabajará es esperpéntica, por degradante: pantalones blancos parecidos a los de un astronauta; zapatos gigantes, de color rojo y blanco; la propia caja con forma de chocolatina, pesada y asfixiante; guantes de cuatro dedos (2013: 21-24). Gutiérrez Pérez ha estudiado esta novela desde el ámbito del derecho laboral y señala cómo la dignidad del trabajador se ve seriamente comprometida en esta escena (2017: 191) y concluye afirmando que «no ha de sacrificarse la dignidad y los derechos ciudadanos del trabajador a toda costa y a cualquier precio» (2017: 192), a pesar de que el protagonista lo acepte «porque no le queda otra solución al protagonista si desea subsistir» (2017: 190).

Aquí es obvia la tergiversación que se produce de la noción de libertad, en el sentido de que el sujeto, aparentemente, es libre de elegir o no dichos trabajos. Como señala Jornet Somoza, el orden neoliberal, en el que la precarización es claramente una seña de identidad, presenta todos sus mecanismos «como capacidad de elección en régimen de libertad (la libertad del mercado) que tiene el efecto de responsabilizar únicamente al sujeto individual de sus malas o buenas decisiones, y por lo tanto también de su situación de precariedad o de fortuna» (2017: 158). El problema es evidente cuando el sujeto es libre solo para elegir entre degradarse al aceptar estos trabajos o quedarse al margen de la sociedad, sin capacidad de subsistir. Obviamente, la coordinadora de la escena ejerce una dominación simbólica sobre el protagonista, algo que se ve perfectamente en el momento en que afirma lo graciosos que están tanto él como su compañero vestidos de mascota y propone hacerles una foto con todo el equipo (López Menacho, 2013: 23). Recuérdese cómo Bourdieu afirma que «hay que hechizar la relación de dominación y de explotación de manera que se transforme en una relación doméstica de familiaridad mediante una serie continua de actos adecuados para transfigurarla simbólicamente eufemizándola» (1997: 171). Sin embargo, aunque las relaciones de explotación se hayan vuelto más sutiles, terminan como siempre, con el sujeto trabajador exhausto.

Como señala Gopegui, apoyándose en Lenin, una de las razones de la anestesia de la población europea es que «cuando las personas tienen 
que vender su fuerza de trabajo, cuando están obligadas a vender, por así decirlo, su disponibilidad, esas personas "no están para política"» e, inmediatamente después, señala cómo el tiempo fuera de sus centros de trabajo no es en absoluto libre, sino que «forma parte de la disponibilidad vendida, es tiempo de reposición y emplearlo en la militancia no deja de ser una lucha agotadora, contrarreloj, a cambio de casi nada» (2004). En este sentido, Antunes ha denunciado cómo para quien trabaja el tiempo libre se convierte, «en buena medida, [en] un tiempo también sujeto a los valores del sistema productor de mercancías» (2001: 104).

Por tanto, el precario de la novela de López Menacho no solo está alienado durante su trabajo, sino que, al salir de él, está demasiado cansado, sin fuerzas para reflexionar sobre su situación y, en última instancia, tratar de subvertir sus condiciones. En definitiva, se le dificulta en grado supremo el recurso a la acción y discurso arendtianos, se le impide desarrollar su faceta política, quedando completamente desactivado frente a la ideología dominante; no en vano, el protagonista se ve en ocasiones obligado a transgredir sus propios principios morales y éticos («Soy el traidor, [trabajo] de espaldas al establecimiento pero también de espaldas a mí mismo» [López Menacho, 2013: 109]) y condenado a la propia autoexplotación. Así, cuando el primer compañero del protagonista, Cristian, abandona su puesto debido al cansancio y al calor, él decide asumir su trabajo y el de su compañero ausente, ocupándose del doble de público, en aras de una responsabilidad excesiva autoimpuesta ("Soy un tío importante, ahora es cuando tengo que demostrar mi valía» [2013: 27]), de una autoexplotación que el protagonista cultiva creyendo que, así, profundiza en su libertad y en su autorrealización, pero que únicamente desemboca en cansancio y depresión (cf.: Han, 2012).

La alienación también se potencia, en primer lugar, por el maltrato y las humillaciones que sufre el protagonista a lo largo de todas sus actividades laborales («[Los niños] me empujan, me arrean, me escupen, me insultan y me menosprecian» [2013: 31]) y, en segundo lugar, por verse condenado a realizar trabajos poco apropiados para su edad («[Todos los compañeros son y serán más jóvenes que yo] en esta crisis que me envejece sin pedir permiso» (2013: 26); "Nadie a sus veintinueve años hace de mascota por cuatro duros» [2013: 30]). Al respecto de la alienación, restan dos ideas por comentar. En primer lugar, en cuanto al empleo de mascota, es importante resaltar cómo el sentido de la vista queda prácticamente suspendido, en dos direcciones: él apenas puede ver el exterior, a causa del sudor y del cristal empañado, pero tampoco puede ser reconocido. Así, el traje de chocolatina es degradante, pero también actúa como una máscara social, que impide que el trabajador sufra vergüenza durante el ejercicio de su actividad ya que no puede ser reconocido. Son precarios absolutamente despersonalizados: si fueran sustituidos por otra persona, nadie se daría cuenta. El trabajador apenas puede aportar valor a su actividad.

La segunda idea relacionada con la alienación que merece ser comentada corresponde al tercer trabajo del protagonista y, en concreto, 
a su último día. El personaje ha promocionado una conocida marca de telefonía y, además de información, ofrece la posibilidad de participar en el sorteo de una bicicleta. El hombre, en ese último día, encuentra a una amiga en su bicicleta, en un claro ejercicio de personificación («Miro mi bicicleta y sólo le veo virtudes. Es austera como yo, está desprovista de lujos, me acerca obediente allá donde le indico, [...] y también te muestra una mirada triste cuando no le haces caso. Sus radios son sus ojos, su cuadro es su boca» [2013: 121]); sin embargo, es justo ese último día en el que va a tener que entregar la bicicleta a la empresa. Esta soledad durante la jornada laboral, esta imposibilidad de establecer lazos de afecto con sus iguales, lo condena a imaginárselos en objetos inanimados.

Relacionada claramente con la alienación, se encuentra una característica del personaje precario de la novela de López Menacho, y es la constatación de que la precariedad ha transformado tanto el marco cognitivo del protagonista, en el sentido de Lakoff (2007), como su propio discurso. En estos momentos de la obra, la consonancia entre el fondo y la forma es absoluta. Se ve bien, por ejemplo, en la derivación («figura de adición formada por la presencia de palabras derivadas de la misma raíz» [Martín Jiménez, 2020: 105]) que plantea el personaje al hablar del paro: «lo peor es la minusvalía moral que te provoca. No ya el paro en sí, sino sentirte parado» (2013: 85), relacionando el propio subsidio con la sensación de detención de la persona que lo cobra, ahondando en la idea de que, si no se está trabajando, no se puede estar en activo. Estas alteraciones cognitivas se ven, también, en dos momentos importantes de la novela:

\footnotetext{
El sábado hice la fotocopia [del mapa de la ruta comercial] en una imprenta y los dos folios de la ruta me costaron 1,35 euros. Es la consecuencia de hacer fotocopias sin preguntar antes el precio: que te cuesta casi un bar auditado» (2013: 98).
}

«[El billete del metro de ida y vuelta] es el $50 \%$ más de lo que gano trabajando durante una hora. O lo que es lo mismo, tengo que trabajar una hora y media para comenzar a ganar dinero» (2013: 110).

Obviamente, la absoluta precariedad en la que vive el sujeto y la falta de un salario digno y suficiente le obligan a conceptualizar cada gasto que realiza como el tiempo que debe estar trabajando para ganarlo. Estamos ante una recreación de la metáfora "el tiempo es dinero», que está muy presente en las sociedades occidentales actuales y que, claramente, está ligada a nuestra cultura y a nuestra sociedad capitalista y acelerada (Lakoff y Johnson, 2015: 45).

\subsection{El compañerismo: difícil tarea}

Las relaciones personales y de solidaridad, que se establecen entre el protagonista y sus compañeros de trabajo son escasas, como es propio en un tiempo de modernidad líquida, en el que las relaciones humanas también se han vuelto precarias (Bauman, 2005). La ideología dominante sabe que, cuanto más solos estén los trabajadores, mejor acatarán el orden establecido: «cuanto más dispersos estemos, cuanto 
menos nos relacionemos y cuanto más débiles y maleables seamos, mejor» (López Menacho, 2013: 87). En este sentido, es relevante la crítica que el protagonista realiza a las empresas que contratan a otras personas para controlar a los trabajadores más precarios y, después, informar sobre ellos. Así, denuncia cómo «la empresa prefiere gastarse dinero en espías antes que dignificar los productos o abaratarlos. 0 mejor, antes que dignificar el salario» (2013: 112).

En general, el protagonista es consciente de la dificultad de establecer lazos sólidos con sus compañeros, no solo por la diferencia de edad que existe, normalmente, entre él y ellos, sino por las propias condiciones laborales. Así, es sintomático el capítulo en el que narra cómo él y su compañero, vestidos de mascotas, tienen que trabajar con dos azafatas con las que las tensiones son constantes. Sobresale, primero, que sea incapaz de individualizarlas ( $Y$ Y no es que me enfurezca con Ana, tal vez sea Judith, por lo que hace» [2013: 74]), algo de lo que se aprovechan la empresa y la ideología dominante, pues es imposible establecer lazos de solidaridad con alguien al que no se reconoce. En segundo lugar, también son importantes las reflexiones que realiza en torno a las azafatas:

Viviendo en la incertidumbre, ya no hay compañeros de trabajo sino enemigos, y ha llegado el momento en el que somos sujetos competencia, rivales o adversarios a extinguir. $Y$ que está bien mostrar que estás por encima del otro o que puedes pisotearle si con ello garantizas tu buena posición. No es culpa suya, en cualquier caso, sino de este mundo miserable (2013: 74).

El propio sistema dinamita los vínculos, obliga a competir por los mismos puestos de trabajo a aquellos que deberían organizarse y pelear, en conjunto, por sus derechos. Como señala López Alós, la competitividad, que él entiende como competencia salvaje, "nos está hablando de la ley del más fuerte y de pura supervivencia. [...] Dicho con rotundidad, la competitividad como principio rector de la vida intelectual y de la producción cultural produce efectos de barbarización» (2019: 62). Recuérdese cómo Remedios Zafra confiesa que, de haber sabido cuando eran jóvenes que solo habría trabajo para unos pocos, «es probable que se hubieran aliado para no crecer o para cortocircuitar las cosas» (2017: 50) pues "cuando el triunfo individual implica el fracaso de los demás es en gran medida un fracaso colectivo» (2017: 52). Aunque en Yo, precario no aparece una reflexión del calado que plantea Zafra, sí persiste la idea de que el otro no puede ser cosificado, no puede ser instrumentalizado para extraer un beneficio.

Esto se hace patente cuando el protagonista está trabajando como anunciante de una marca de telefonía y se da cuenta de que, al lado de la tienda, se ha sentado una indigente a la que algunos paseantes «donan calderilla y prosiguen su camino. La caridad ganándole la batalla a la justicia social» (2013: 117). Este sentimiento reivindicativo dura poco porque, enseguida, el personaje se da cuenta de que la mujer gana más que él: si él está a 4,9 euros la hora, calcula que ella recauda entre siete y diez euros en el mismo tiempo. Confiesa que le parece injusto que gane más que él, pero inmediatamente se arrepiente de este 
pensamiento («Cómo he llegado al punto en que siento envidia y celos de una indigente es un fantasma que me atormentará los próximos días» [2013: 118]). Lo solventará ofreciéndole un zumo. En ese momento, entiende que ella sentada "como una gárgola del desamparo» y él, con la bici, de alguna manera, se acompañan (2013: 119). Es reseñable cómo el protagonista de Yo, precario evita caer en maniqueísmos: el personaje es complejo, con sus aciertos y sus miserias. En último término, prevalece el sentido humano, pues este protagoniza un claro ejemplo de reconocimiento del otro, de la dignidad y valor de la indigente. Solo así es posible un futuro hermanamiento de los subalternos.

\subsection{Espacio y tiempo enfermos en la precariedad}

El cronotopo bajtiniano de la novela, es decir, la relación singular entre el tiempo y el espacio que se da en el texto es síntoma de la enfermedad del sujeto. Se ve bien en el ambiente decadente de algunos de los lugares en los que trabaja, como un cine "que ha quedado desfasado», "vestigio de otra España», en cuyos servicios, donde los trabajadores se cambian, hay «un cartel que pone SERVEIS, cuya segunda E está colgando, como queriéndose suicidar» (2013: 51).

Quizá el tiempo sea aún más enfermizo. El día a día del sujeto es rutinario, se ven las mismas caras, se emiten los mismos mensajes («Son siempre las mismas personas haciendo las mismas cosas, enredados todos en las telas de la rutina» [2013: 122]); sin embargo, la necesidad de trabajar más y la autoexplotación del propio sujeto en aras de ganar más dinero —un buen ejemplo es el trabajo de la auditoría de las máquinas de tabaco- hacen que la rutina, un tiempo circular que se cierra sobre sí mismo, cruce con un tiempo cronológico que se devora a sí mismo, el tiempo de la prisa, de la aceleración, de la imposibilidad de descansar; todo ello, claro, aumenta el cansancio del cuerpo (Concheiro, 2016: 74). Véase cómo el tiempo circular, en esta novela, no tiene ninguna de las connotaciones que le daban los griegos (el Aión eterno, el tiempo que no muere), sino que aparece como síntoma de la imposibilidad del progreso del protagonista.

En este sentido, hay una escena relevante en la novela ubicada en un centro comercial (un «no-lugar» por excelencia, además de, por supuesto, un emblema de la propia sociedad de consumo) donde el protagonista reflexiona sobre cómo «se ve que las horas no pasan ya como dicta el tiempo, sino que es el tiempo quien se somete a las personas. Se ha vuelto prisionero de sí mismo. Se ha enroscado en su espiral de minutos y segundos» (2013: 70). En esta intervención hay presentes dos ideas importantes: primero, la masificación del rebaño, pues todo el mundo ha subido a comer a los restaurantes de la planta de arriba al mismo tiempo y, por ende, todos bajarán también a la vez; en segundo lugar, está presente una enorme circularidad temporal, que conlleva con claridad la alienación y, en definitiva, la disolución del sujeto político. 


\section{4. ¿Es posible la subversión del orden dominante?}

Hasta ahora, se ha visto cómo el sujeto que protagoniza la novela Yo, precario, es un sujeto en disolución, debido a múltiples factores: la falta de trabajo estable, la alienación, autoexplotación e, incluso, distorsión del marco cognitivo que sufre; la imposibilidad de establecer vínculos de solidaridad y, por último, una relación enfermiza con el espacio y el tiempo. Visto esto, ¿hay posibilidad de subvertir el orden dominante? ¿Hay esperanza de que sea posible algún tipo de revolución?

Es reseñable cómo en ningún caso se defiende un ocio escapista; por ejemplo, en relación con el espectáculo del fútbol, se crítica el excesivo jolgorio que provoca la victoria de la Selección Española en medio de un tiempo de recortes sociales («España es tan insuperable en el terreno de juego como su gente exhibiendo sus miserias. Celebrarán la victoria de unos millonarios aunque no tengan con qué llenar sus jarras» [López Menacho, 2013: 170]). En este sentido, coincide con Marta Sanz cuando critica que la cultura se reduzca al espectáculo y señala cómo estos "circos» benefician al orden dominante pues, "después, frente a la agresión real de la hipoteca, ya hemos gastado la adrenalina» (2014: 2021).

Está claro que el protagonista es consciente de su clase y de la situación en la que vive; así, sostiene con rotundidad que no le gusta este orden (2013: 74). La subversión puede intentarse con una crítica directa, descarnada, que se da en algunos momentos de la novela; así, el personaje afirma cómo, «con el afán recaudatorio del Estado, el primero en vivir por encima de sus posibilidades, todos somos víctimas. Todos, menos los poderosos. El monstruo se devora a sí mismo por los pies» (2013: 92) o se reafirma en que «es preferible no tener dinero pero tener dignidad a no tener ninguna de las dos cosas» (2013: 95). Incluso hay algún momento en el que cae ligeramente en una crítica simplona hacia el gobierno de Rajoy (2013: 144-145).

Sin embargo, hay connatos de subversión y resistencia más interesantes. Por ejemplo, la simpatía que, en su trabajo como mascota, le despierta un niño, lo que le demuestra las pequeñas satisfacciones que puede encontrar en el trabajo más ridículo («[Marcos me enseña que] aunque yo tenga perdida la guerra, hay batallas que aún puedo ganar» (2013: 37). Esto le llevará a querer trabajar «no sólo para pagar el alquiler, sino también por dignificar este empleo» (2013: 42). En otra ocasión, se imagina en su propio "día de la marmota», que él denomina «Mascot Day» y piensa cómo podría atracar el Banco Santander con su disfraz de mascota: «robarle un botín a Botín, que está harto de robarnos a nosotros, qué ilusión. El nuevo Robin Hood, con la sonrisa perenne como V (de Vendetta) y sabor a chocolate» (2013: 55). Además de la antanaclasis creada con el apellido del director del banco, es interesante la desmitificación que hace de sí mismo incluso imaginándose como un superhéroe. La épica tampoco resiste la precariedad. En toda la novela, el humor y la ironía, en su faceta más revulsiva, están muy presentes. El propio personaje confiesa que se toma «las cosas con el suficiente 
humor como para restarles trascendencia» (2013: 96)». Acierta Manuel Rivas cuando afirma que «el Precario es un héroe de la ironía (2013: 9).

Además de esta ironía, del humor, el sujeto, aún en descomposición, mantiene y se reafirma en ocasiones en sus propios principios, en un afán de resistencia y de resiliencia; por ello, sostiene que esta crisis no puede terminar devorándolo (2013: 96). En algunos momentos, el autor recrea bien aquella idea sartreana de que el hombre es lo que hace con lo que hicieron de él. En último término, como dice Manuel Rivas, «es la humanidad resistente, no precaria, no subalterna, no sometida, la que narra» (2013: 10). Por eso, cuando al final de la novela consigue un trabajo de al menos tres meses como redactor de contenidos publicitarios - y el hecho de que se plantee un final optimista también es muy relevante porque permite visualizar una posibilidad de escape, una línea de fuga y supervivencia- está convencido de que «sí, todo va a salir bien» (2013: 165), aunque no debe olvidarse que el nuevo trabajo sigue dentro de los estándares de la lógica publicitaria.

El mayor acto de resistencia - aunque siempre a pequeña escala, sin grandes épicas - en el que el propio protagonista se convierte en un caballo de Troya contra el sistema, representado ahora por la compañía telefónica, es en el momento en que decide ofrecer participar en un sorteo de una bicicleta únicamente a gente que, intuye, tiene poco poder adquisitivo (2013: 115). Así, consigue que no tengan que dar sus datos personales ni comprar ningún producto para poder acceder al sorteo e intenta que se lleven por una vez un regalo «en vez de que alguien les robe», y lo hace como un «infiltrado en el ejército enemigo» (2013: 112). En ese momento, tiene lugar una fantástica intervención:

\footnotetext{
Me doy cuenta de que me he convertido casi en un guardián. $Y$ siento que hay un montón de hombres jugando como niños en un campo de asfalto. $Y$ están solos. Quiero decir que no hay nadie aún mayor vigilándolos. Sólo yo soy el responsable de todos ellos. Estoy al borde de un precipicio y mi trabajo consiste en evitar que los hombres se despeñen por él. En cuanto empiezan a correr sin mirar adónde van, yo salgo de donde esté y los cojo. Eso es lo que me gustaría hacer todo el tiempo en este trabajo de mierda. Vigilarlos. Yo sería el guardián entre el asfalto (2013: 113).
}

Obviamente, se trata de un juego metaliterario con el monólogo de Holden Caufield, el protagonista de El guardián entre el centeno (Salinger, 2010: 216), con el que también comparte esa nota de humor descarnado dentro de una atmósfera asfixiante. El personaje de Yo, precario está en el borde del precipicio, pero entiende que vale la pena seguir adelante, resistir, si con ello evita que otros se despeñen por él. Por eso, dicho gesto no se puede entender en términos de caridad, porque no hay jerarquía entre el protagonista y la gente a la que intenta beneficiar, sino solamente solidaridad. No existe mejor ejemplo de subversión del egoísta orden dominante.

\section{Conclusiones}

En este artículo se ha puesto de manifiesto que la novela de Javier López Menacho, Yo, precario, publicada en 2013, es un perfecto representante 
de una interesante producción novelística actual en español, que entronca con el realismo social de mediados del siglo $X X$ y que apuesta por llevar al terreno literario las condiciones materiales de los protagonistas para intentar subvertirlas, entendiendo el texto ficcional como uno de los muchos campos en los que se puede, y se debe, dar batalla.

También, se ha relacionado la novela con la nueva clase social del precariado que, entre otros, ha teorizado Guy Standing, y se ha demostrado cómo su protagonista se construye como un sujeto en crisis por varios motivos: la ausencia de trabajo estable, la alienación, autoexplotación e, incluso, distorsión del marco cognitivo que sufre; la dificultad de establecer vínculos de fraternidad con sus compañeros, a los que ve como individuos contra los que solo puede competir $y$, en último lugar, una relación enfermiza con el espacio y el tiempo. No obstante, la novela también plantea a través de la ironía, el humor y la metaliteratura una vía de resistencia, una línea de fuga que ilustra las posibilidades de subvertir el orden dominante, afirmando cómo cualquier tipo de victoria pasa por una necesaria solidaridad entre los sujetos explotados.

Queda claro cómo los textos literarios, al igual que los demás discursos que una sociedad teje para explicarse a sí misma, deben ser tenidos en cuenta para comprender correctamente la situación presente, y poder combatirla. Yo, precario, en fin, se revela una obra importante para la reflexión sobre el cambio de paradigma económico, aunque también social y cultural, que se está imponiendo en la actualidad.

\section{Notas}

* Esta investigación se enmarca en el Proyecto de Investigación «La construcción discursiva del conflicto: territorialidad, imagen de la enfermedad e identidades de género en la literatura y en la comunicación social» (Ref.: FFI2017-85227-R). El autor ha recibido financiación pública a través de una ayuda FPU (16/05577). 


\section{Bibliografía citada}

ALBERCA, M. (2007): El pacto ambiguo: de la novela autobiográfica a la autoficción, Madrid: Biblioteca nueva.

ANTUNES, R. (2001): ¿Adiós al trabajo? Ensayo sobre las metamorfosis y la centralidad del mundo del trabajo, São Paulo: Cortez Editora.

ARENDT, H. (2005): La condición humana, Barcelona: Paidós.

BAUMAN, Z. (2005): Amor líquido: Acerca de la fragilidad de los vínculos humanos, México: Fondo de Cultura Económica.

BECERRA MAYOR, D. (2013): La novela de la no-ideología, Madrid: Tierradenadie Ediciones.

BECERRA MAYOR, D. (2015): Convocando al fantasma. Novela crítica en la España actual, Madrid: Tierradenadie.

BECERRA MAYOR, D.; ARIAS CAREAGA, R.; RODRÍGUEZ PUÉRTOLAS, J.; SANZ, M. (2013): Qué hacemos con la literatura, Madrid: Akal.

BÉRTOLO, C. (2008): La cena de los notables, Cáceres: Periférica.

BLAUBERG, I. (1971): Diccionario marxista de filosofía, Méndez García, A. (trad.), México: Ediciones de cultura popular.

BOURDIEU, P. (1997): Razones prácticas. Sobre la teoría de la acción, Barcelona: Anagrama.

CABALLÉ, A. (2017): "¿Cansados del yo?», Babelia, (El País), <www.elpais.com/cultura/2017/01/06/babelia/1483708694_145058.html>, [29/01/2020].

CONCHEIRO, L. (2016): Contra el tiempo, Filosofía práctica del instante, Barcelona: Anagrama.

GIORDANO, C. (2018): Articulaciones del inconsciente ideológico del capitalismo tardío en la narrativa posmoderna: tres casos de estudio, Tesis Doctoral, Universidad Complutense de Madrid, <https://eprints.ucm.es/id/eprint/49374/1/T40274.pdf>, [29/01/2020].

GOPEGUI, B. (2004): «El árbol y los plátanos», La Jiribilla de papel, núm. 36 (Noviembre), <https://rebelion.org/el-arbol-de-los-platanos>, [29/01/2020].

GOPEGUI, B. (2019): Rompiendo algo. Escritos sobre literatura y política, Barcelona: Debolsillo.

GUTIÉRREZ PÉREZ, M. (2017): «Yo, precario» en Luján Alcaraz, J., Baviera Puig, I. y Hierro Hierro, F. J. (coords.), El derecho del trabajo en la literatura, Murcia: Ediciones Laborum, 187-192.

HACKING, I. (2001): ¿La construcción social de qué?, Buenos Aires: Paidós.

HAN, B-C. (2012): La sociedad del cansancio, Barcelona: Herder.

JORNET SOMOZA, A. (2017): «Nuestro cuerpo también: pensar en precario en la España de la crisis», Artes del ensayo. Revista internacional sobre el ensayo hispánico, núm. 1, 153-182.

LAKOFF, G. (2007): No pienses en un elefante, Madrid: Editorial Complutense. LAKOFF, G.; JOHNSON, M. (2015): Metáforas de la vida cotidiana, Madrid: Cátedra.

LÓPEZ ALÓS, J. (2019): Crítica de la razón precaria, Madrid: Catarata.

LÓPEZ MENACHO, J. (2013): Yo, precario, Barcelona: Los libros del lince.

LYOTARD, J. F. (2006): La condición posmoderna, Madrid: Cátedra.

MARTÍN JIMÉNEZ, A. (2020): Compendio de retórica, Valladolid: edición del autor.

MORA, V. L. (2013): La literatura egódica. El sujeto narrativo a través del espejo, Valladolid: Universidad de Valladolid.

PUJANTE SÁNCHEZ, D. (2011): «Teoría del discurso retórico aplicada a los nuevos lenguajes. El complejo predominio de la elocutio», Rétor, vol. 1, núm. 2, 186-214.

PUJANTE SÁNCHEZ, D. (2018): «La construcción discursiva de la realidad en el marco de la retórica. La Retórica Constructivista», Tonos Digital, núm. 34, 131. 
RIVAS, M. (2013): «El vacío lleno (Prólogo)» en López Menacho, J., Yo, precario, Barcelona: Los libros del lince, 9-11.

RODRÍGUEZ, J.C. (2013): De qué hablamos cuando hablamos de marxismo, Madrid: Akal.

RODRÍGUEZ, J.C. (2017): Teoría e historia de la producción ideológica, Madrid: Akal.

SALINGER, J. D. (2010): El guardián entre el centeno, Madrid: Alianza Editorial SANZ, M. (2014): No tan incendiario. Textos políticos que salen del cenáculo, Cáceres: Periferia.

STANDING, G. (2018): El precariado. Una nueva clase social, Barcelona: Pasado y presente.

VALDIVIA, P. (2016): "Narrando la crisis financiera de 2008 y sus repercusiones», $452^{\circ} \mathrm{F}$. Revista de Teoría de la Literatura y Literatura Comparada, núm. 15 , 18-36,

<https://revistes.ub.edu/index.php/452f/article/view/16322/31890>, [29/01/2020].

VATTIMO, G. (2010): Adiós a la verdad, Barcelona: Gedisa.

ZAFRA, R. (2017): El entusiasmo. Precariedad y trabajo creativo en la era digital, Barcelona: Anagrama. 